\title{
Diets with High Amino Acid Density Can Improve Broiler Performance and Increase in Profit
}

\author{
N.K. Sharma ${ }^{1}$ and N. Sharma ${ }^{2}$ \\ Institute of Agriculture and Animal Science \\ Tribhuvan University \\ Rampur, Chitwan \\ ${ }^{2}$ Himalayan College of Agricultural Science and Technology \\ Purbanchal University \\ Gatthaghar, Bhaktapur \\ 1email: nishchalks@gmail.com
}

\begin{abstract}
This study was conducted at the Institute of Agriculture and Animal Science (IAAS), Rampur, Chitwan for evaluating performance and carcass characteristics of broilers fed with two grades of diets varying in nutrient densities; high amino acid density (HG) diet and medium amino acid density (MG) diet. Two hundred and eighty straight run unsexed Cobb 500 broiler chicks were randomly assigned to two treatment groups with seven pens per treatment such that each pen consisted of 20 chicks. Control birds received MG diet in three phase feeding system viz. pre-starter: 1-15 days, starter: 16-25 days, and grower: 26-38 days. Treatment birds received HG diet in two phase feeding system viz. starter: 1-15 days, and grower: 16-38 days. The birds were provided with diets in crumbled form. At 38 days, with HG diet, feed conversion ratio (FCR) decreased $(\mathrm{p}<0.05)$ by $13.72 \%$; body weight, carcass yield, and breast meat increased $(\mathrm{p}<0.05)$ by $15.45 \%, 2.92 \%$ and $10.46 \%$ respectively. Total feed intake and incidence of mortality among two treatments remained unaffected. At day 38, HG diet produced net profit of NRs. 20.97 per bird. It is suggested that HG diets give better performance with respect to weight gain, FCR, carcass yield and net profit compared to MG diets.
\end{abstract}

Key words: broiler, carcass, FCR, feed intake, nutrient density

\section{Introduction}

Poultry sector is undergoing rapid commercialization in Nepal since a decade. This sector shares around 3$4 \%$ of the total GDP (MoAC 2011). The population of commercial broilers and layers has reached 32 and 7.48 million respectively in 2010/11 and the total poultry population is estimated to be around 39.5 million (MoAC 2011). The poultry sector has been growing at a rate of $10 \%$ per annum over the last decade (Ryan \& Pant 2011). The net meat production during the year 2010/11 was 2,77,625 mt, out of which the contribution from chicken was 36,085 mt (MoAC 2011). There are around 50 feedmills, including 11 pellet mills, producing 4,50,000 mt of feed per annum ((Ryan \& Pant 2011).

Broiler chickens share around $81 \%$ of the total poultry population in Nepal (MoAC 2011). These are also the major meat type birds in Nepal. More than $70 \%$ of the commercial broilers raised in Nepal are heavy breeds. Majority of these breeds are Cobb 500/400, Hubbard, Marshall, LIR, Ross 308, etc. They are generally marketed at $1.5-2.5 \mathrm{~kg}$ body weight in around 38-50 days of age. However, during the time of less chicken demand or low ready bird prices, they are kept up to 3$3.5 \mathrm{~kg}$ body weight and gradually marketed as the price progresses. Farmers are paid more for the birds which are greater than $2 \mathrm{~kg}$ live weight. So, they are more willing to sell the birds at least an average weight of 2 $\mathrm{kg}$. This will generate more profit for them. On an average, Nepalese poultry raisers generally produce 4-5 batches of broiler chickens per annum. Dietary modifications could decrease the slaughter age of the birds and produce more than six batches of broilers 
per annum. Use of high amino acid density (HG) diets could be one of such dietary modifications.

Feed is the major tool to extract total genetic capabilities from the birds besides good housing and management. Several previous researches have demonstrated improved performance of birds by the use of high nutrient density diets. Dietary nutrient density is one of several nutritional factors that has a significant impact on the growth and health of broiler chickens, which in turn affect the economics of broiler production (Mabray \& Waldroup 1981, Reece \& Mc Naughton 1982, Campbell et al, 1988). Manipulation of nutrient density has been shown to affect growth performance and carcass quality (Jones \& Wiseman 1985). Lott et al. (1992) reported higher body weight and improved feed efficiency with high-energy rations. High nutrient density diets improve growth performance and meat yield (Holsheimer \& Reusink 1993, Dozier \& Moran Jr 2001). Fortifying diets with a higher proportion of amino acids from 1 to $35 \mathrm{~d}$ of age is advantageous with respect to meat yield when broilers are marketed at heavy body weight (Kidd et al, 2004). As the nutrient level in feed increases, the cost of feed will increase but the revenue generated will also increase due to bird's high level of performance. This trial aimed to see the performance and carcass characteristics of broilers on HG diets and economics associated with it.

More than $90 \%$ of broiler farmers in Nepal use commercially available feed and about $65 \%$ of them are pellet feed users. There are around 11 pellet feed industries in Nepal each with a capacity of more than 200mt per day. More than $90 \%$ of the Nepalese feed industries are currently practicing a 3-4 phase feeding system for broilers viz. B0 (Broiler prestarter), B1 (Broiler starter), B2 (Broiler grower) and B3 (Broiler finisher). A downtime associated with production of four varieties of products in a feed mill is high because of adding the additional diets. This study would also test two phase feeding system for broilers (with HG starter and grower diets). If the net profit associated with this feeding program comes higher at farmer's level, only two types of broiler feed products could be manufactured by Nepalese feed industries, as this will reduce the downtime involved in changing the products and increase feed mill efficiency.

\section{Methodology}

This study was conducted in 2012 A.D at the Institute of Agriculture and Animal Science (IAAS) livestock farm, Chitwan, Rampur. Two hundred and eighty straight run day old unsexed Cobb 500 broiler chicks were randomly sampled from the hatchery for the study. The birds were divided into two treatment groups with one group based on MG diet and the other based on HG diet. Each treatment was replicated seven times with each replicate/pen consisting of twenty chicks. This way each of the treatment groups consisted of 140 chicks. The birds were reared in deep litter system made up of rice husk. Each pen was provided with equal sized feeder and drinker. Feed and water were provided ad libitum. The feed was manufactured in crumbled form by Probiotech Industries Pvt Limited (Nimbus), Nepal.

The composition of diets and their proximate values are presented in Table 1 and 2.

Table 1. Composition of diets

\begin{tabular}{|c|c|c|c|c|c|}
\hline Ingredients & B1HG & B2HG & B0MG & B1MG & B2MG \\
\hline Maize & 188 & 231 & 210 & 186 & 191 \\
\hline Soybean meal & 314 & 242 & 261 & 225 & 183 \\
\hline MB M & 35 & 40 & 35 & 25 & 25 \\
\hline DORB & - & - & - & 52 & 81 \\
\hline Rice Polish & 88 & 88.39 & 102.14 & 109.85 & 118.88 \\
\hline Wheat & 300 & 325 & 300 & 300 & 300 \\
\hline Broken Rice & 50 & 50 & 50 & 50 & 50 \\
\hline Limestone & 6.75 & 4.61 & 9.11 & 10.65 & 9.62 \\
\hline Soya Oil & 3.5 & 5.5 & - & - & - \\
\hline Mustard DOC & - & - & 20 & 30 & 30 \\
\hline Salt & 2.75 & 1.5 & 2.75 & 1.5 & 1.5 \\
\hline Sodium bicarbonate & 1.0 & 1.5 & 1.5 & 2.0 & 1.50 \\
\hline L lysine HCL & 1.80 & 1.90 & 1.83 & 1.75 & 1.70 \\
\hline D L Methionine & 1.65 & 1.50 & 1.40 & 1.070 & 0.97 \\
\hline L Threonine & 0.45 & 0.60 & 0.43 & 0.55 & 0.86 \\
\hline Betaine & 2 & 1.5 & 2 & 1.5 & 1.5 \\
\hline Mycosorb & 0.50 & 0.50 & 0.50 & 0.50 & 0.50 \\
\hline Vitamins/Minerals & 1.50 & 1.50 & 1.50 & 1.50 & 1.50 \\
\hline Lincomed & 0.08 & 0.10 & 0.08 & 0.08 & 0.08 \\
\hline Coccidiostat & 0.21 & 0.55 & 0.21 & 0.55 & 0.55 \\
\hline Econase $\mathrm{XT}$ & 0.10 & 0.10 & 0.10 & 0.10 & 0.10 \\
\hline Quantum 5000 & 0.20 & 0.20 & 0.15 & 0.15 & 0.15 \\
\hline Eurotiox & 0.04 & 0.04 & 0.03 & 0.03 & 0.03 \\
\hline Others & 2.47 & 2.01 & 0.27 & 0.22 & 0.56 \\
\hline Total, $\mathrm{Kg}$ & 1000 & 1000 & 1000 & 1000 & 1000 \\
\hline
\end{tabular}

B1HG- High amino acid density starter, B2HG- high amino acid density grower, B0MG- medium amino acid density prestarter, B1MG- medium amino acid density starter, B2MGmedium amino acid density grower. 
N.K. Sharma \& N. Sharma/Diets with High.......

Table 2. Proximate value of the diets

\begin{tabular}{l|l|l|l|l|l}
\hline Nutrient composition & B1HG & B2HG & B0MG & B1MG & B2MG \\
\hline ME (Kcal/kg) & 2980 & 2980 & 2932 & 2932 & 3000 \\
CP \% & 22.49 & 20.54 & 22.07 & 21.67 & 19.74 \\
EE \% & 4.43 & 4.33 & 4.70 & 4.70 & 5.56 \\
CF \% & 4.51 & 4.60 & 3.80 & 3.78 & 3.06 \\
Calcium \% & 1.01 & 0.92 & 1.35 & 1.32 & 1.12 \\
Total Phosphorous \% & 0.73 & 0.66 & 0.55 & 0.55 & 0.6 \\
Dig. Lysine \% & 1.20 & 1.10 & 1.10 & 1.020 & 0.88 \\
Dig. Methionine (M)\% & 0.44 & 0.42 & 0.40 & 0.39 & 0.35 \\
Dig. M+Cysteine\% & 0.86 & 0.82 & 0.79 & 0.76 & 0.69 \\
Dig. Tryptophan\% & 0.19 & 0.19 & 0.18 & 0.17 & 0.16 \\
Dig. Threonine\% & 0.78 & 0.75 & 0.71 & 0.69 & 0.62 \\
Dig. Arginine\% & 1.26 & 1.19 & 1.15 & 1.10 & 0.97 \\
Dig. Isoleucine\% & 0.80 & 0.76 & 0.74 & 0.70 & 0.62 \\
Dig. Valine\% & 0.92 & 0.88 & 0.85 & 0.82 & 0.71 \\
\hline
\end{tabular}

Note: B1HG- High amino acid density starter, B2HG- high amino acid density grower, B0MG- medium amino acid density pre-starter, B1MG- medium amino acid density starter, B2MG- medium amino acid density grower.

Table 3. Feeding program

\begin{tabular}{l|l|l|l|l|l}
\hline Treatments & $\begin{array}{l}\text { HG starter } \\
\text { (B1HG) }\end{array}$ & $\begin{array}{l}\text { HG grower } \\
\text { (B2HG) }\end{array}$ & $\begin{array}{l}\text { MG pre-starter } \\
\text { (B0MG) }\end{array}$ & $\begin{array}{l}\text { MG starter } \\
\text { (B1MG) }\end{array}$ & $\begin{array}{l}\text { MG grower } \\
\text { (B2MG) }\end{array}$ \\
\hline T1 & - & - & $1-15$ days & $16-25$ days & $26-38$ days \\
T2 & $1-15$ days & $16-38$ days & - & - & - \\
\hline
\end{tabular}

HG- High amino acid density, MG- Medium amino acid density

Weight gain, feed intake and FCR were measured on 15 th and $38^{\text {th }}$ day. All the twenty birds from each replicate/pen were weighed with the help of electronic balance and the average age was recorded. For carcass measurements, 2 birds from each pen, i.e, 14 birds from each treatment were used. Birds were fasted for 12 hours (ad libitum water was provided) before slaughter for studying carcass characteristics. Carcass yield was recorded by international method (head, neck, feet and viscera were removed). Economic assessments were based on diet costs and live weight gains. Diet cost was based on retail price of feed as provided by manufacturer (Probiotech Industries, Pvt. Ltd) at the time of the trial.

The experiment was conducted in a completely randomized design (CRD). For significance test, one way analysis of variance (ANOVA) was performed. Treatment means were compared by least significant difference $(\mathrm{p}<0.05)$ using $\mathrm{M}$ - Stat C Version 1.3.

\section{Results and Discussion}

Performance of broilers under different dietary treatments

There was no significant difference $(P>0.05)$ in feed intake between the treatment groups till day 15 or day 38 (Table 4). However, HG diets improved body weight $(\mathrm{P}<0.05)$ measured at 38 days of age. The body weight was increased by $266 \mathrm{~g}$ which is $15.45 \%$ more than the group fed with MG diet. Similarly, there was significant improvement in FCR $(\mathrm{P}<0.05)$ through $\mathrm{HG}$ diet 
(Table 4). Feeding high amino acid density diets decreased FCR by 28 points or $13.72 \%$. Kidd et al. (2004) reported an $11 \%$ increase in 49 day body weight with Ross $\times$ Ross 508 broilers which were provided diets formulated to a high amino acid density vs. moderate amino acid density.

Table 4. Effects of medium and high amino acid density diets on the performance of broilers

\begin{tabular}{|c|c|c|c|c|c|c|c|}
\hline \multirow[t]{2}{*}{ Dietary } & \multicolumn{4}{|c|}{ Feed intake (g) } & \multirow{2}{*}{$\begin{array}{l}\text { Body } \\
\text { weight (g) } \\
38 \text { days }\end{array}$} & \multirow{2}{*}{$\begin{array}{l}\text { Corrected Feed } \\
\text { Conversion } \\
\text { ratio (FCR) }\end{array}$} & \multirow{2}{*}{$\begin{array}{l}\text { Mortality } \\
(\%)\end{array}$} \\
\hline & $\begin{array}{l}1-15 \\
\text { days }\end{array}$ & $\begin{array}{l}\text { 16-25 } \\
\text { days }\end{array}$ & $\begin{array}{l}\text { 26-38 } \\
\text { days }\end{array}$ & $\begin{array}{l}\text { 1-38 } \\
\text { days }\end{array}$ & & & \\
\hline MG diet & $567^{\mathrm{a}}$ & 1068 & 1884 & $3519^{a}$ & $1721^{\mathrm{b}}$ & $2.04^{\mathrm{a}}$ & 4.28 \\
\hline HG diet & $565^{\mathrm{a}}$ & 2941 & & $3506^{\mathrm{ab}}$ & $1987^{\mathrm{a}}$ & $1.76^{\mathrm{b}}$ & 3.57 \\
\hline
\end{tabular}

${ }^{\mathrm{a} b \mathrm{~b}}$ Means within a column not sharing a common superscript differ significantly $(P<0.05)$

FCR was corrected for mortality by adding the weight of the dead birds.

The mortality rate among two dietary treatments remained unaffected with less than 1 percent difference in mortality (Table 4).

\section{Carcass characteristics of broilers under different dietary treatments}

Carcass yield and breast meat yield were significantly higher $(P<0.05)$ in HG diet group (Table 5). Carcass yield and breast meat yield were increased by $2.92 \%$ and $10.46 \%$ respectively.

Table 5. Effects of medium and high amino acid density diets on carcass characteristics

\begin{tabular}{l|c|c}
\hline Dietary & \multicolumn{2}{|c}{ Percentage of live body weight at day 38 } \\
\cline { 2 - 3 } Treatments & Carcass & Breast muscle \\
\hline MG diet & $68.45^{\mathrm{b}}$ & $20.45^{\mathrm{b}}$ \\
HG diet & $70.45^{\mathrm{a}}$ & $22.59^{\mathrm{a}}$
\end{tabular}

${ }^{\mathrm{a}-\mathrm{b}}$ Means within a column not sharing a common superscript differ significantly $(P<0.05)$

Sibbald and Wolynetz (1986) found similar increment in breast meat yield with high lysine containing feed.

\section{Economic analysis}

The use of HG diets in T2 till day 38 could produce a net gain of NRs. (112.81-91.84)/bird, i.e, net gain of NRs. 20.97 per bird compared to T1 based on MG diets (Table 6).

In Nepal, barter system is predominant in poultry business. In this system, dealers provide chicks to the farmers and purchase ready birds from their farms. Farmers are paid as per total kilograms of live bird weighed. So, profitability to farmers is measured as per unit of live weight gain rather than the carcass weight. In some cases, producers have their own slaughter
Table 6. Economics of broiler production in terms of feed cost and return

\begin{tabular}{l|l|l}
\hline Feed Type & \multicolumn{2}{|c}{$\begin{array}{c}\text { Average feed consumed/ } \\
\text { bird (in kg) and cost } \\
\text { involve }\end{array}$} \\
\hline & T 1 & T 2 \\
\cline { 2 - 3 } MG pre-starter & 0.567 & 0 \\
Cost @ NRs. 39.80 /kg & 22.57 & 0 \\
MG starter & 1.068 & 0 \\
Cost @ NRs. 38.15/kg & 40.74 & 0 \\
MG grower & 1.884 & 0 \\
Cost @ NRs. 36.40/kg & 68.58 & 0 \\
HG starter & 0 & 0.565 \\
Cost @NRs. 42.55/kg & 0 & 24.04 \\
HG grower & 0 & 2.941 \\
Cost @ NRs. 41.30/kg & 0 & 121.46 \\
Total feed consumed per bird (kg) & 3.519 & 3.506 \\
Feed cost/bird in NRs. (x) & 131.89 & 145.50 \\
Avg live wt/bird (Kg) & 1.721 & 1.987 \\
Avg income per bird @ Rs. 130/kg & & \\
live wt (y) & 223.73 & 258.31 \\
Feed cost/kg live wt. of bird (NRs.) & 76.63 & 73.22 \\
Return to farmer/ live bird in NRs. & 91.84 & 112.81 \\
(y-x): cost of chicks(NRs. 40/chick) & & \\
and other non-feed cost not included & & \\
\hline
\end{tabular}

HG- High amino acid density, MG- Medium amino acid density, T1- Medium amino acid density (MG) diet group, T2- High amino acid density (HG) diet group.

house/fresh house. Carcass weight is of utmost importance in such cases.

Thus, with high amino density (HG) diets birds attain marketable weight earlier and it is possible to increase number of batches of chickens produced per year. 
Birds in medium amino acid density (MG) diets will take some more days and some more feed to attain the same weight. So, even if we calculate the profitability after the birds attain the same weight as of HG diet, we save that extra amount of feed intake and extra days that are needed to produce the same weight. For producers who have their own slaughter house/fresh house, profitability by using HG diet is even higher due to increment of $2.92 \%$ in carcass yield.

Nepali poultry market has turned volatile since few years where price of chicks and ready birds are unpredictable. Last few years' trend show that the demand for chickens and ready bird prices are higher for almost half a year. For rest of the time, it is difficult for the farmers to sell the chickens on time due to surplus in the market. So, it would be wise to think on the use of HG diets around the time when the demand together with the price is expected to increase. When the demand is high, it is profitable to produce chickens of marketable weight as early as possible.

\section{Acknowledgements}

This was a trial conducted at the Institute of Agriculture and Animal Science (IAAS) livestock farm, Rampur, Chitwan. We are highly thankful to Probiotech Industries Pvt. Ltd (PBT) for providing broiler feeds to carry out this experiment. Special thanks goes to Mr. Sanjay Gami for assisting us in laboratory works and providing valuable data; and Dr. Dinesh Gautam, Chief Technical Officer of PBT, for his constructive suggestions throughout the trial.

\section{References}

Campbell, G.L., R.E. Salmon and H.L. Classen. 1988. Effect of nutrient density on broiler carcass composition as influenced by age. Nutr. Rep. Int. 37:973-981.

Dozier, W.A. and E.T. Moran Jr. 2001. Response of early and late developing broilers to nutritionally adequate and restrictive feeding schedules during the summer. $J$. Appl. Poult. Res. 10:92-98.

Holsheimer, J.P. and E.W. Ruesink. 1993. Effect on performance, carcass composition, yield, and financial return of dietary energy and lysine levels in starter and finisher diets fed to broilers. Poult. Sci. 72:806815.

Jones, R.L. and J. Wiseman. 1985. Effect of nutrition on broiler carcass composition: Influence of dietary energy content in the starter and finisher phases. $\mathrm{Br}$. Poult. Sci. 26:381-388.

Kidd, M.T., C.D. Mcdaniel, S.L. Branton, E.R. Miller, B.B. Boren and B.I. Fancher. 2004. Increasing aminoacid density improves live performance and carcass yields of commercial broilers. J. Appl. Poult. Res. 13:593-604.

Lott, B.D., E.J. Day, J.W. Deaton and J.D. May. 1992. The effect of temperature, dietary energy level, and corn particle size on broiler performance. Poult. Sci. 71:618-624.

Mabray, C.J. and P.W. Waldroup. 1981. The influence of dietary energy and amino acid levels on abdominal fat pad development of the broiler chicken. Poult. Sci. 60:151-159.

MoAC, 2011. Statistical information on Nepalese agriculture. Government of Nepal. Agriculture Information and Communication Centre. Ministry of Agriculture and Cooperative. Hariharbhawan, Lalitpur.

National Research Council. 1994. Nutrient requirements of poultry. 9th rev. ed. National Academic Press, Washington, DC.

Reece, F.N. and J.L. McNaughton. 1982. Effects of dietary nutrient density on broiler performance at low and moderate environmental temperatures. Poult. Sci. 61:2208-2211.

Ryan, O. and A. Pant. 2011. International Finance Corporation builds farming capacity in Nepal. New Business Age. www. new businessage.com/Sectoral/ 580.

Sibbald, I.R. and M.S. Wolynetz. 1986. Effects of dietary lysine and feed intake on energy utilization and tissue synthesis by broiler chicks. Poultry Sci. 65:98-105. 
Nepal Journal of Science and Technology Vol. 13, No. 1 (2012) 